\title{
A guerra literária da Independência
}

\section{Marcello Basile}

NEVES, Lúcia Maria Bastos Pereira das. Corcundas e constitucionais: a cultura politica da Independência (1820-1822). Rio de Janeiro: Revan / Faperj, 2003. 477 p.

Algumas teses acadêmicas - poucas, é verdade - desde o ritual de defesa já se credenciam como marcos historiográficos. Por vezes, tornam-se quase uma espécie de best-sellers nãopublicados entre o público especializado, se levados em conta sua reprodução e circulação por meio do velho e o sempre inconveniente sistema de fotocópias. Não raro, contudo, é preciso aguardar alguns anos até que o trabalho seja, afinal, lançado sob a forma de livro. É exatamente este o caso da Tese de Doutorado de Lúcia Maria Bastos Pereira das Neves, professora titular de História Moderna da UERJ; defendida em 1992 na USP, sob a orientação de Maria Beatriz Nizza da Silva, só agora, depois de tantas vezes citada em produçôes acadêmicas subseqüentes, é publicada e disponibilizada para um público mais amplo, interessado em conhecer aspectos da Independência do Brasil até então não abordados ou ainda insuficientemente explorados pela historiografia brasileira e portuguesa.

O caminho privilegiado pela autora é o de enfocar este processo à luz da cultura política da época, entendida em sentido abrangente, de maneira a contemplar não apenas as idéias e seus fundamentos, mas também, nos termos metafóricos em que se organiza o livro, o cenário, os atores, a platéia e a seqüência de atos do drama da Independência. Para isso, analisou, pela primeira vez em tais dimensóes e profundidade, um impressionante conjunto de mais de três centenas de folhetos políticos e de três dezenas de jornais, publicados no Brasil e em Portugal, além de diversas outras fontes manuscritas e impressas encontradas em arquivos de ambos os países, que lhe permitiram fazer uma ampla reconstituição dos debates e dos acontecimentos que marcaram as relações luso-brasileiras entre os anos de 1820 e 1822 . Na linha dos 
estudos de linguagem política de John Pocock e Quentin Skinner, a autora identifica e analisa uma ampla gama de conceitos fundamentais do novo vocabulário político em pauta, tais como despotismo, escravidão, sistema colonial, liberdade, liberalismo, constituição, pacto social, igualdade, soberania, fraternidade, ilustração, civilização, progresso, regeneração, reforma, revolução, eleição, cidadão, direitos, anarquia, jacobino, demagogo, império, nação, pátria, povo, plebe, pés-de-cabra, pés-de-chumbo, corcunda e outras tantas expressóes afins, discutidas didaticamente na imprensa periódica e, sobretudo, panfletária; trabalho este indispensável para a compreensão das idéias e das práticas políticas em seus diversos matizes, e que cumpre realizar para outros contextos pós-Independência. Surgia, então, uma rede de debates abrangendo os dois lados do Atlântico, revelando inédita preocupação com o político.

Assim esboçava-se - e eis aqui outro elemento inovador da obra, retomando o instigante conceito de Habermas - uma esfera pública política e literária, mediante o desenvolvimento da imprensa e a maior circulação de informações para além do público letrado. Em uma socie- dade ainda muito marcada pela cultura da oralidade, as camadas iletradas da população entravam em contato com as novas idéias por meio das leituras coletivas em voz alta de impressos fixados nas praças e ruas, das conversas e discussões em livrarias, boticas, casas de pasto e botequins, das festividades cívicas, das manifestações de protesto, das representaçōes teatrais e mesmo dos sermões nas igrejas. Era a voz das ruas, aspecto por tanto tempo ignorado pela historiografia. Os próprios redatores de folhetos e jornais expressavam sua preocupação em instruir um público mais amplo nos princípios do constitucionalismo monárquico, em formar uma opinião pública, e dotavam suas publicações de uma estrutura e de uma retórica favoráveis a essa difusão, com textos em forma de diálogos, hinos, sonetos e até orações políticas, escritos em linguagem mais coloquial e didática. Contudo, ainda muito restrita e pouco diversificada, em razão do elevado grau de analfabetismo, forjada de cima para baixo e ameaçada por práticas persistentes de censura, perseguiçõoes e prisões contra publicistas, cerceando o livre desenvolvimento das idéias, essa opinião pública embrionária não logrou constituir-se plenamente 
neste momento, fazendo daquele público mais amplo uma "platéia na sombra”. Daí também o caráter tênue e restrito dessa esfera pública, abalada ainda mais por ações repressivas durante o Primeiro Reinado.

Outra importante contribuição de Corcundas e constitucionais é o extenso inventário prosopográfico dos agentes efetivos desse processo: as elites política (deputados das Cortes de Lisboa, procuradores das províncias) e intelectual (redatores de jornais, autores de folhetos) lusobrasileira, tarefa que, dada a escassez de informações biográficas, implica pesquisa meticulosa e cruzamento de fontes. O resultado geral é semelhante ao perfil da elite política imperial já antes traçado por José Murilo de Carvalho: uma homogeneidade mais cultural - proporcionada, sobretudo, pela formação na Universidade de Coimbra - do que social, e o predomínio de magistrados, clérigos e militares no conjunto dessas elites. Quanto às suas concepções e posicionamentos políticos, destacavam-se dois grupos, ainda que com certos matizes e intercâmbios individuais. De um lado, a chamada elite coimbrã, que reunia adeptos de um liberalismo moderado favorável a uma monarquia centralizada, com predomínio do Poder
Executivo sobre o Legislativo e soberania compartilhada entre o rei e os representantes da nação; homens como os irmãos Andrada (José Bonifácio, Antonio Carlos e Martim Francisco), José da Silva Lisboa, Azeredo Coutinho, Araujo Lima, Nicolau Vergueiro, Camara Bittencourt, frei Sampaio e Hipólito da Costa, mais apegados à idéia reformista ilustrada de um grande império luso-brasileiro. De outro, a elite brasiliense, mais radical, que almejava uma monarquia com menor concentração de poderes, predominando o Poder Legislativo sobre o Executivo e calcada na soberania do povo; congregava indivíduos, em sua maioria, sem formação universitária ou integrantes da elite intelectual, como Gonçalves Ledo, Januário da Cunha Barbosa, Clemente Pereira, Alves Branco, João Soares Lisboa, Lopes Gama, frei Caneca, Cipriano Barata, Muniz Tavares e Diogo Feijó, que acabaram se transformando nos ideólogos da Independência. Se ambos os segmentos rivalizavam na disputa pela formação e conquista da opinião pública e pelo apoio de dom Pedro, e chegaram mesmo a se confrontar em face de questóes mais polêmicas (como o tipo de eleição - direta ou indireta - para a Assembléia Constituinte, em junho de 
1822), mantiveram-se, todavia, unidos até Independência, em comum desacordo com as medidas cada vez mais ameaçadoras às pretensões autonomistas brasileiras estabelecidas pelas Cortes de Lisboa.

Os conflitos no interior das elites luso-brasileiras, bem como nas relações entre Brasil e Portugal até às vésperas $\mathrm{da}$ Independência, eram diluídos, entretanto, pelo compartilhamento da mesma cultura política, cujos fundamentos ideológicos a autora localiza na peculiaridade das mitigadas Luzes portuguesas, cultivadas durante a época pombalina e, inclusive, após a Viradeira de Maria I. Este ambiente comum, que mesclava a secularização e o pragmatismo ilustrados com o tradicional apego à religião e a uma visão estamental da sociedade, explica a moderação do liberalismo vintista e a ausência de projetos democráticos ou republicanos no processo de emancipação; e, sobretudo, ajuda a entender, primeiro, a força da idéia de império luso-brasileiro, acalentada, como demonstraram Kenneth Maxwell e depois Maria de Lourdes Lyra, desde a chamada geração de 1790, e, ainda, a coalizão no Brasil em torno de dom Pedro, seja como forma de preservar os direitos brasileiros no âmbito do Reino Unido, seja, no fim das contas, como caminho seguro para a construção de um Estado independente. Corcundas e constitucionais, portanto, sepulta de vez as interpretações historiográficas - já anteriormente questionadas, mas sem maior desenvolvimento, por autores como Maria Odila Dias e Ilmar Mattos - que viram a Independência como revolução, transcorrida em termos da simples oposição entre colônia e metrópole, em lugar de uma transação (o que não implica negar ou minimizar a face conflituosa e violenta desta negociação, manifesta por lutas em algumas províncias e por manifestações antilusitanas cotidianas), e a colaram de maneira estanque à formação da nacionalidade brasileira. Afinal, as identidades regionais ainda iriam por muito tempo se sobrepor à nacional (haja vista que o termo pátria aludia muitas vezes à cidade ou província de origem, e não tanto ao país ou nação); e até o início de agosto de 1822 - como apontam os artigos na imprensa e os manifestos redigidos por Gonçalves Ledo e José Bonifácio neste mês - ainda se nutriam esperanças de união com Portugal nos moldes de uma monarquia dual. Foi a recusa das Cortes de Lisboa em aceitar tais aspirações, aliado a uma série de mal-entendidos decorrentes 
das distâncias e dificuldades de comunicação entre os dois países, que acabaram levando ao rompimento, embalado pelo ideário liberal.

Todo este processo é minuciosamente analisado por Lúcia Neves: o Vintismo, as polêmicas na imprensa brasileira e portuguesa, as eleições, os debates, posicionamentos e deliberações nas Cortes, os impasses em torno da volta de dom João VI para Portugal, do Fico, da criação do Conselho de Procuradores das Províncias e da convocação da Assembléia Constituinte, a situação tensa e controversa nas províncias, os movimentos contestatórios e as celebraçôes cívicas na Corte, a Aclamação e a Coroação de dom Pedro I, e, por fim, a deflagração aberta do conflito entre coimbrãos e brasilienses logo após a Independência, com a vitória do primeiro sobre o segundo grupo e a repressão desencadeada pelo ministro José Bonifácio contra seus adversários. $\mathrm{O}$ Império do Brasil, conclui a autora, nascia, assim, sob a égide do absolutismo ilustrado. O conceito, próprio a alguns Estados europeus na segunda metade do século XVIII, como Portugal, é questionável para uma nação de fato fundada em instituiçôes e princípios liberais estranhos àquele contexto, ainda que, como a
França da Restauração, comportando boa dose de conservadorismo; mas não deixa de evidenciar o que seria a marca primordial de dom Pedro e de todo o Primeiro Reinado: a ambigüidade de um liberalismo mitigado pela persistência da escravidão e de resíduos do Antigo Regime.

Corcundas e constitucionais inaugurou, portanto, uma série de outros importantes trabalhos sobre a Independência e a construção do Império brasileiro produzidos no último decênio, como os de Iara Lis Carvalho Souza, Isabel Lustosa, Gladys Sabina Ribeiro e Marco Morel, abordando aspectos diversos desse processo, referentes às representações simbólicas em torno do poder monárquico e da imagem de dom Pedro I, à virulência dos debates jornalísticos de antanho, aos conflitos antilusitanos e à formação do espaço público na Corte do Rio de Janeiro. E, para aqueles que por ventura ainda se sintam incomodados com o modo como acabou sendo realizada a separação política brasileira, a obra oferece uma perspectiva mais instigante e original de análise; pois se a Independência não foi marcada por uma grande guerra de libertação nacional contra o jugo da metrópole portuguesa, por certo 
$372 \cdot$ Marcello Basile

ensejou, como bem percebeu Luis ca, uma verdadeira "guerra literária", Gonçalves dos Santos, o padre Pe- que inundou Brasil e Portugal de rereca, em famoso folheto da épo- panfletos e folhas volantes. 